\title{
The Virtuous and Evil in Chinese Culture: Personality Structure and Connotation
}

Liying Jiao, Yan Xu, Ying Yang; Faculty of Psychology, Beijing Normal University

The idea of virtuous and evil characteristics has a long history in Chinese language and culture, there are abundant descriptions of virtuous and evil characteristics in human nature. However, the specific structures of virtuous and evil concepts have not yet been clearly delineated, and detailed studies of these concepts are limited. It is important to carefully define the content of virtuous or evil personality, and understand the psychological structure of the two concepts.

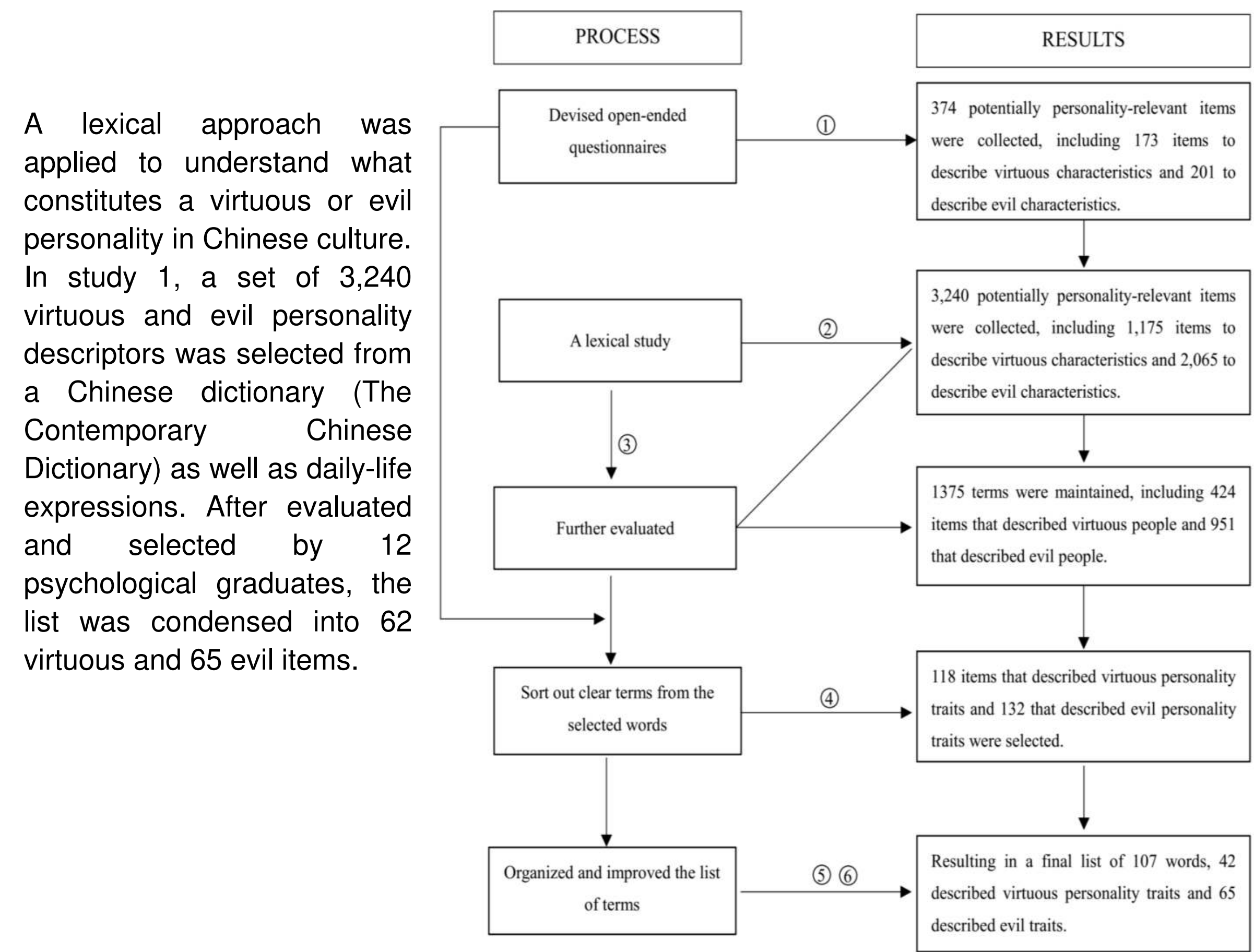

In study 2, we explored the dimensions of virtuous personality using exploratory factor analysis (EFA) with sample $1(n=313)$ and confirmatory factor analysis (CFA) with sample $2(n=518)$. Results revealed that good personality contained four dimensions: conscientiousness and integrity, altruism and dedication, benevolence and amicability, and tolerance and magnanimity. We refined the four-dimensions good personality lexical rating scale, which contained 27 items.
In Study 3, we used the same method as in Study 2 to explore the structure of an evil personality (EFA: Sample 1, $\mathrm{n}=367$; CFA Sample 2, $n=269$ ). Results showed the evil personality contained four dimensions: atrociousness and mercilessness, mendacity and hypocrisy, calumniation and circumvention, and faithlessness and treacherousness. Thus, we employed a 28 -item evil personality lexical rating scale. The internal consistency, reliability, and criterion-related validity of the two scales were verified.

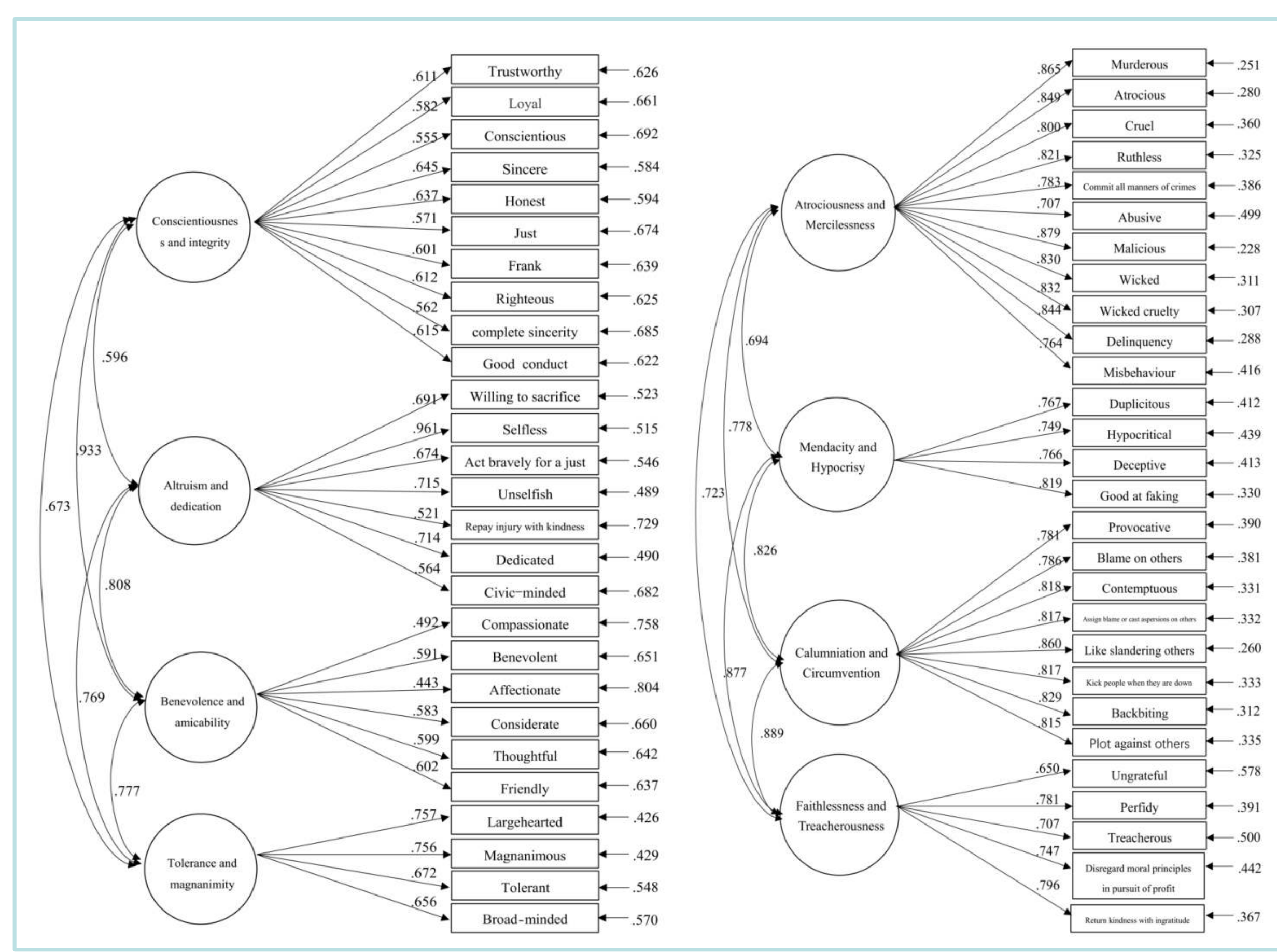

In China, Confucius regards benevolence as the highest moral principle for a person. Therefore, virtuous and evil traits are naturally embedded in the personality structure of Chinese people. Understanding the structure of virtuous and evil are useful for researchers who are interested in Chinese culture as well as the studies in Chinese indigenous psychology. 